\title{
Intravenous acetaminophen: questions on new perioperative applications for Canadian anesthesiologists
}

\author{
Philippe Richebe, MD, PhD, DESAR (1)
}

Received: 16 August 2019/Revised: 13 December 2019/Accepted: 21 December 2019/Published online: 8 January 2020

(c) Canadian Anesthesiologists' Society 2020

\section{To the Editor,}

Acetaminophen was discovered at end of the $19^{\text {th }}$ century $^{1}$ and has since been extensively used for its analgesic properties. ${ }^{2}$ Traditionally administered orally (PO), its intravenous (IV) formulation was approved in Europe in 2002, in the United States in 2011, and by Health Canada in 2018. With this new resource now available to Canadian anesthesiologists, inevitable questions arise as to whether the IV formulation should be used and what evidence support its use in the perioperative period instead of other traditional (and less expensive) oral versions.

Before these questions can be addressed, it is important to understand the drug's historical advances regarding its analgesic properties. In the 1970s, acetaminophen was believed to primarily act on peripheral and central cyclooxygenases. A more recent hypothesis proposed that acetaminophen also augments the activity of the descending bulbo-spinal serotoninergic inhibitory pain pathway. ${ }^{3}$ Importantly, acetaminophen's analgesic effect relies on a sufficient concentration of acetaminophen at central sites and thus must rapidly, though passively, cross the blood-brain barrier to reach a threshold concentration in the cerebrospinal fluid (CSF). ${ }^{4}$ Thus, the faster and higher the concentration peaks in the plasma, the higher the CSF concentration.

Various studies have reported a plasma concentration of $15 \mu \mathrm{g} \cdot \mathrm{mL}^{-1}$ for an analgesic effect in $50 \%$ of patients. More recently, Singla et al. measured the plasma and CSF acetaminophen concentrations after rectal (PR), PO, or IV

P. Richebe, MD, PhD, DESAR ( $)$.

Department of Anesthesiology and Pain Medicine, University of Montreal, Maisonneuve-Rosemont Hospital, Montréal, QC, Canada

e-mail: philippe.richebe@umontreal.ca administration. They concluded that $100 \%$ of patients in the IV group had a plasma concentration above the 15 $\mu \mathrm{g} \cdot \mathrm{mL}^{-1}$ analgesia threshold level, as opposed to only $28 \%$ and $0 \%$ in the PO and PR groups, respectively. ${ }^{5}$ Moreover, when PO acetaminophen was concomitantly administered with IV morphine, the plasma concentration did not reach the same $15 \mu \mathrm{g} \cdot \mathrm{mL}^{-1}$ threshold as it had for the IV group. ${ }^{6}$

For perioperative pain management, acetaminophen is often part of a multimodal strategy that is recommended in many guidelines. ${ }^{7}$ It also has fewer contraindications and side effects than nonsteroidal anti-inflammatory drugs. Although meta-analyses have reported that IV acetaminophen versus placebo is effective for managing postoperative pain, ${ }^{8}$ whether IV is superior to PO for the treatment of postoperative pain remains controversial. ${ }^{9}$ Safety and side effects following IV acetaminophen administration were similar to those following PO administration, with the same precautions in the elderly population.

Enhanced recovery after surgery programs have recently gained increased clinical adoption and allow for a quick return to oral intake and thus to $\mathrm{PO}$ acetaminophen. Nevertheless, anesthesiologists still have to manage postoperative pain in some patients for whom the return to oral intake is delayed and who will not benefit from PO acetaminophens analgesic effect because of its poor absorption. This is even more evident if opioids are used perioperatively, exacerbating surgery-related decreases in gastrointestinal motility.

As such, anesthesiologists might consider using IV acetaminophen as part of their analgesic regimen. Nevertheless, the IV formulation is more expensive (approximately 300 times more than a same PO dose). Ideally, anesthesiologists should limit the treatment duration to minimize pain management costs. For 
example, limiting IV acetaminophen to only one dose at anesthesia induction to cover intraoperative nociception and to one to two doses postoperatively until PO options return, would be reasonable to minimize additional costs. In a recent retrospective analysis involving more than 700 USA hospitals, a reduction in global perioperative costs and hospital length of stay when using IV acetaminophen was reported..$^{10}$ A randomized-controlled trial also reported that this optimal analgesia could reduce postoperative delirium in the elderly. ${ }^{11}$

As Health Canada has now approved the use of IV acetaminophen, it is important for Canadian anesthesiologists to comprehensively assess whether IV acetaminophen can help in their perioperative pain management strategies while considering various concerns of its application, including but not limited to cost management.

Conflict of interest statement Philippe Richebe received honoraria as a consultant for Medasense, Abbvie, Medtronic-Covidien, Biosyent, Merck, and Avirpharma. Avirpharma manufactures and sells IV acetaminophen in Canada (honoraria to prepare and give three video conferences on acetaminophen to Canadian pharmacists, anesthesiologists, and surgeons were paid to Dr Richebe). He has been a member of the Scientific Advisory Board of Medasense Ltd. since 2014.

Funding statement Department of Anesthesiology and Pain Medicine.

Editorial responsibility This submission was handled by Dr. Hilary P. Grocott, Editor-in-Chief, Canadian Journal of Anesthesia.

\section{References}

1. Von Mering J. Beitrage zur Kenntniss der Antipyretica. Ther Monatsch 1893; 7: 577-87.
2. Bertolini A, Ferrari A, Ottani A, Guerzoni S, Tacchi R, Leone S. Paracetamol: new vistas of an old drug. CNS Drug Rev 2006; 12: 250-75.

3. Mallet C, Daulhac L, Bonnefont J, et al. Endocannabinoid and serotoninergic systems are needed for acetaminophen-induced analgesia. Pain 2008; 139: 190-200.

4. Mallet C, Barrière DA, Eschalier A. Paracetamol: a promising ancestor (French). Therapie 2012; 67: 277-81.

5. Singla NK, Parulan C, Samson R, et al. Plasma and cerebrospinal fluid pharmacokinetic parameters after single-dose administration of intravenous, oral, or rectal acetaminophen. Pain Pract 2012; 12: $523-32$

6. Raffa RB, Pawasauskas J, Pergolizzi JV Jr, et al. Pharmacokinetics of oral and intravenous paracetamol (acetaminophen) when co-administered with intravenous morphine in healthy adult subjects. Clin Drug Investig 2018; 38: 259-68.

7. Chou R, Gordon DB, de Leon-Casasola OA, et al. Management of postoperative pain: a clinical practice guideline from the American Pain Society, the American Society of Regional Anesthesia and Pain Medicine, and the American Society of Anesthesiologists' Committee on Regional Anesthesia, Executive Committee, and Administrative Council. J Pain 2016; 17: 131-57.

8. De Oliveira GS Jr, Castro-Alves LJ, McCarthy RJ. Single-dose systemic acetaminophen to prevent postoperative pain: a metaanalysis of randomized controlled trials. Clin J Pain 2015; 31: 8693.

9. Kendall MC, Hickman SR. Possible confounders in study of oral versus i.v. acetaminophen for postoperative pain control. Am J Health Syst Pharm 2018; 75: 1093-4.

10. Hansen RN, Pham AT, Boing EA, Lovelace B, Wan GJ, Urman $R D$. Reduced length of stay and hospitalization costs among inpatient hysterectomy patients with postoperative pain management including IV versus oral acetaminophen. PLoS One 2018; DOI: https://doi.org/10.1371/journal.pone.0203746.

11. Subramaniam B, Shankar P, Shaefi $S$, et al. effect of intravenous acetaminophen vs placebo combined with propofol or dexmedetomidine on postoperative delirium among older patients following cardiac surgery: The DEXACET randomized clinical trial. JAMA 2019; 321: 686-96.

Publisher's Note Springer Nature remains neutral with regard to jurisdictional claims in published maps and institutional affiliations. 